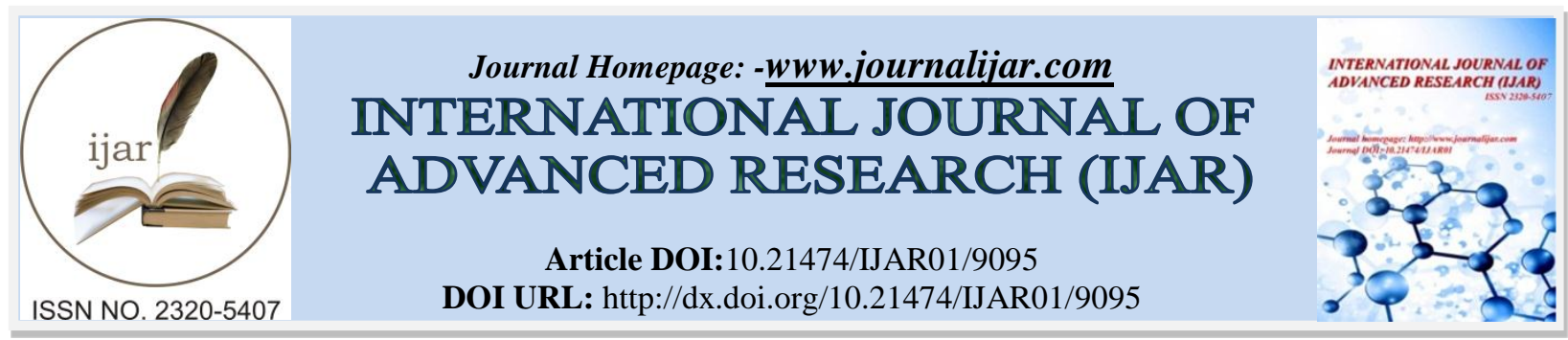

RESEARCH ARTICLE

\title{
ASSESSING THE PRACTICES AND CHALLENGES OF COMMUNITY BASED HEALTH INSURANCE IN ETHIOPIA: THE CASE OF OROMIA NATIONAL REGIONAL STATE DISTRICT OF GIMBICHU.
}

\author{
Gutama Namomsa. \\ Ambo University, College of Business and Economics, Department of Public Administration and Development \\ Management, Ambo, Ethiopia.
}

\section{Manuscript Info}

Manuscript History

Received: 20 March 2019

Final Accepted: 22 April 2019

Published: May 2019

Key words:-

Community Based Health Insurance,

Practices, Challenges and Gimbichu.

\section{Abstract}

The study assessed the community based health insurance practice \& challenges in Oromiya national regional state, Gimbichu woreda. In order to achieve these goals primary data have been collected from members of Community based health insurance by taking 135 respondents from five gands by using simples stratified sampling. Three employees of CBHI were contacted for in-depth interview \& one manager of CBHI Finfine branch also has been contacted for triangulation purpose. The data were putted in SPSS version 21 in order to get descriptive statistics or result. The Qualitative data collected via in-depth interviews \& open ended questions were analyzed through transcription in to micro-soft word processing then by categorizing \& coding on their theme.

The enrolment of the CBHI in Gimbichu woreda is significant even many people being the member of the insurance since 2014 (60.7\%) this will have positive impact on the progress of the CBHI in the woreda. Number of non-indigent members of the insurance is 10,911 whereas indigent member of the insurance is 2,380 so the overall progress of the woreda on membership type especially on the paying group is good.

Both demand (In the health institution the attitude of the health employees is very less, there is shortage of medicines, absence of the nearest hospital in the wored, lack of skilled manpower assigned for the CBHI and supply side problems (Not taking their membership ID on time by presenting at the office Not fulfilling the necessary requirement during registration) responsible for less enrollment of the insurance.

Copy Right, IJAR, 2019,. All rights reserved.

\section{Introduction:-}

A country's economic development is closely interrelated with the health status of its population. An efficient and equitable health care system is an important instrument to break up the vicious circle of poverty and ill health (Wiesmann and Jutting 2000).

Countries use different means of financing the health system in order to provide fair \& equitable services to the general public Health financing systems through general taxation or through the development of social health

Corresponding Author:-Gutama Namomsa.

Address:-Ambo University, College of Business and Economics, Department of Public Administration and Development Management, Ambo, Ethiopia. 
insurance are generally recognized to be powerful methods to achieve universal coverage with adequate financial protection for all against healthcare costs. These systems intend to respond to the goal of fairness in financing, in that beneficiaries are asked to pay according to their means while guaranteeing them the right to health services according to need. In tax-funded systems, the population contributes indirectly via taxes, whereas in social health insurance systems, households and enterprises generally pay in via contributions based on salaries or income (Carrin et al. 2005).

Many low-income countries experience difficulties in achieving universal financial protection (van Ginneken 1999a). A tax-funded health system may not be easy to develop, due to the lack of a robust tax base and a low institutional capacity to effectively collect taxes. Social health insurance has traditionally started by insuring workers. A further nationally organized expansion of social health insurance to the self-employed and non-formal sector is especially demanding (ILO 2001) as citied by Carrin et al. (2005).

In the 1980s and early 1990s, a number of developing countries introduced user fees in order to access health care services. While such schemes increased the availability of health facilities and improved the quality of services, at least to some extent (Ndiaye et al., 2007; Carrin et al., 2005) they also created financial barriers (Jutting, 2004; Wiesmann and Jutting, 2000; Xu et al., 2003) as citied in Anagaw (2015).

But many countries since the late 1990s, due to the financial difficulties associated with the imposition of user fees, a number of low and middle income countries have introduced community-based health insurance (CBHI) schemes. CBHI schemes are a hybrid between traditional risk sharing and market based formal insurance arrangements (Ahuja and Jutting,2004).

The health financing system, including CHIs, cannot be looked at in a vacuum but needs to be connected to the broader goals of the health system (Bennett 2004). In the World Health Report 2000, the WHO (2000) proposed the following health system's goals: contribute to good health, be responsive to people's expectations and establish fairness in the financial contributions to the health system. Financial contributions for health are considered as fair when health expenditure of households is distributed according to ability to pay rather than to actual costs incurred as a consequence of illness. In order to achieve these ambitious goals, the World Health Report 2000 distinguishes four functions for the health system to fulfill: (i) the provision of health services; (ii) the creation of the necessary investment and training resources for health; (iii) health financing; and (iv) government stewardship.

In Sub-Saharan Africa, formal and well-functioning health insurance schemes generally exist for few people who are employed in formal sectors. For the majority, health care is accessed and/or covered from own source of money which is mostly sourced from existing funds or assets, this mostly leads to least use of health care services (carrin et al 2005).

Like traditional risk management systems, CBHI schemes are local initiatives built upon the principles of social solidarity and common benefits to provide financial protection against the impoverishing effects of health expenditure (Ahuja and Jutting, 2004; Tabor, 2005; Jacobs et al., 2008) as cited by Anagaw (2015).

Despite major strides to improve the health of the population in the last one and half decades, Ethiopia's population still face a high rate of morbidity and mortality and the health status remains relatively poor. Vital health indicators from the DHS 2005 show a life expectancy of 54 years (53.4 years for male and 55.4 for female), and an IMR of $77 / 1000$. Under-five mortality rate has been reduced to 101/1000 in 2010v. Although the rates have declined in the past 15 years, these are still very high levels.

The major health problems of the country are largely preventable communicable diseases and nutritional disorders. More than $90 \%$ of child deaths are due to pneumonia, diarrhea, malaria, neonatal problems, malnutrition and HIV/AIDS, and often as a combination of these conditions (FMOH, 2014).

Based on the 2007 national health account around 7.14 USD were spending per person. Compared to the world health organization standard which estimated around 34 USD per person per annum is much higher than the national health accounts. Thus spending for health expenditure were so low and the expenditure were accounted from different sections and sectors accordingly around $31 \%$ from government, $37 \%$ from donor/development organizations and direct from user fees are 30\% (FMOH, 2009). 


\section{Statement of the problem}

In terms of access to modern health care and various other health indicators, Ethiopia ranks low even as compared to other Sub Saharan African countries. For instance, the 2014 Global Multidimensional Poverty Index (MPI) report ranks Ethiopia 107th on acute multidimensional poverty indicators among 108 countries (Oxford Poverty and Human Development Initiative, 2014). Life expectancy is 63 years while the under-five mortality rate stands at 68 per 1000 live births and the maternal death rate at 420 per 100,000 live births (WHO, 1990).

The three main sources for financing the Ethiopian health system are international development assistance from bilateral and multilateral donors ( 40 percent), out-of pocket health spending by individuals (37 percent) and the public budget (21 percent) (WHO,2010).

Because of high reliance on OOP health care spending, coping with health shocks could be catastrophic for households particularly for the ultra-poor. Due to limited access to a well-developed health insurance system, only about 2 percent of private healthcare expenditure was covered by private insurance institutions, which is very low compared to other Sub-Saharan African countries like Kenya (8.8\%), and Benin (7.3\%), Senegal (17.9\%) (ibid). As part of its health care financing strategy in general and its health insurance strategy in particular, the Government of Ethiopia endorsed and launched community-based health insurance (CBHI) schemes in 13 pilot woredas in Amhara, Oromia, Southern Nations, Nationalities, and Peoples (SNNP), and Tigray regions in 2010/11 to provide risk protection mechanisms for those employed in the rural and the informal sectors. Three years on, the government has decided to scale up CBHI, with schemes in 161 woredas (EHIA, 2015).

As Study conducted by Robyn et al. (2012) identified that provider payment can affect provider participation, satisfaction and retention in CBI; the quantity and quality of services provided to CBI patients; patient demand of CBI services; and population enrollment, risk pooling and financial sustainability of CBI.

The Cohen et al. (2012) study is merely focused on the impact of premium payment made by the members on CBI as most of study showed premium payment is one factor that can determine the CBI. Hence this study has the gap of narrow scope it only focus on the effect of supply side effect on CBI performance.

In LMICs, while CBHI schemes may be helpful in the short term to address the issue of improving the rural population and informal workers' access to health services, they still face challenges. Lack of funds, poor quality of care, and lack of trust are major reasons for low CBHI coverage in LMICs. If CBHI schemes are to serve as a means to providing access to health services, at least in the short term, then attention should be paid to the issues that militate against their success (Adebayo et al. 15). The study conducted by Adebayo is broadly scoped on challenges responsible for low coverage of CBHI but this study doesn't shows prominent factors responsible to these problems or factors that cause this challenges.

Haile (2014) conducted a research on Willingness to join community based health insurance among rural households of Debub, Bench District, Bench Maji Zone, South west Ethiopia. Most of the demographic, socioeconomic variables and social capital were found to be significantly associated with willingness to join community based health insurance. This study merely focused only on factors that determine the communities demand to join or not join the scheme. This study has the gap of not looking the implementation of the scheme and encounter challenges beside this the study focused on the non-members of the scheme.

In general studies on CBHI, in Ethiopia are scarce. Existing available limited studies are primarily focus on single case and apply quantitative method. Among this studies for instance, study conducted by Angaw et al. (2015) on uptake of scheme shows that almost all insured households want to renew and majority of uninsured want to enroll. Hilina (2014) in her study on Socio-economic determinants of CBHI, identified that human capital variables such as (household age, education, attend local meeting) have positive impact on households to become the members of CBHI. Bedacho et al. (2016) studied the Customer satisfaction on CBHI pilot district and find that users' satisfaction with CBHI was high. They found that age, family size, laboratory services provision, health services provider friendliness, CBHI offices opening times, membership card collection process, and time interval to use of services were significant predictors of satisfaction with $\mathrm{CBHI}$. 
Analyzing the extent of scheme implementation by using quantitative method, may not be sufficient to identify major responsible factors for the expansion of the implementation of scheme in the different districts of Ethiopia particularly, Gimbichu woreda. This study aims to contribute to fill this gap.

\section{Objectives of the study \\ General objective of the study}

The overall objective of this study was to assess the major challenges that have impact on the enrollment of CBHI in the Gimbichu woreda.

\section{Specific objectives of the study}

1. To assess the practice/implementation level of the Community based health insurance in the Gimbichu woreda.

2. To examine major benefited that communities are getting from member shipment of the insurance

3. To identify the challenges affecting the implementation of the scheme from both the service provider and gainer part.

\section{Research Question}

The following research questions guide this study:

1. To what extent the CBHI is implemented and what are challenges of implementation in the Gimbichu woreda?

2. How does the CBHI implementation can be improved?

3. What are the main benefits the community is getting from the CBHI?

\section{Significance of the study}

This study examines the enrollment and challenges of CBHI in the Gimbichu districts. It helps to provide information and data for concerning bodies about the current progress (enrollment) of CBHI in the district it is significant to give signal to the district scheme initiators and other responsible bodies to take remedial action, to allows policy making for future view of the district by considering the current approach of community health insurance in the woreda and focusing on the capacitating the scheme regarding membership and service provision in the district.

Generally, the study helps the Woreda to identify the existing gaps between the challenges and the Practice of CBHI in each villages of the district. Besides, the study will increase focus and attention of different stakeholders (such as FMOH, PFSA, NGO's and various CBHI initiators) towards the current progress of CBHI such as increasing catchment areas (villages), increasing membership, and rendering good health services beside this it will give clue about contemporary challenges faced by the district in regarding the CBHI.

\section{Scope of the study}

This study scopes itself on health insurance even if there are various insurance types the study tries to scope on the health insurance. Currently there are two types of health insurance policies in Ethiopia health sectors, namely Social health insurance (focused on insuring the employees engaged in formal sector of the economy) and second one is Community Based Health Insurance (CBHI, Which focused on the all societies participated on non-formal sectors of the country's economy) hence, this study is emphasized on the second health policy that is Community Based Health Insurance by excluding the Social Health Insurance (SHI) (EHIA, 2015).

Among various issues of $\mathrm{CBHI}$ this research investigate the enrollment and practices by focusing on Oromiya regional state, Gimbichu district. In this study only members of CBHI is included than non-members of CBHI. This study is time framed between the academic years of 2017-2018.

\section{Literature Review}

\section{Definition and concept of Health insurance}

Health insurance is the way to distribute the financial risk associated with the variation of individuals' health care expenditures by pooling costs over time through pre-payment and over people by risk pooling (OECD, 2004).

Community based health insurance is a type of insurance for informal sectors through contributing some amount of money that is owned, designed, and managed by their members, and the schemes are a not-for profit type of health insurance that has been used by poor people to protect themselves against the high costs of seeking medical care and treatment for illness (Uzochukwu et al. 2010). It is mainly financed by the contributions/premium regularly collected from its members (Chankova et al 2008). 
Community Based Health Insurances have the potential to provide financial protection for underserved segments within the population, minimizing the equity gap and reducing out-of-pocket spending, increase awareness regarding the value of insurance, building self-belief among participants through community control mechanisms, and enhancing utilization of the health care system (Shemeles 2012).

Community financing for health is referred to as a mechanism whereby households in a community (the population in a village, district or other geographical area, or a socio-economic or ethnic population group) finance or cofinance the current and/or capital costs associated with a given set of health services. At the same time they are expected to gain participation in the management of the community financing scheme and the organization of the health services (Carrin et al. 2005).

If universal healthcare coverage is to be financed through insurance, the risk pool needs the following characteristics: i) compulsory contributions to the risk pool (otherwise the rich and healthy will opt out); ii) the risk pool has to have large numbers of people, as pools with a small number cannot spread risk sufficiently and are too small to handle large health costs; and iii) where there is large number of poor, pooled funds will generally be subsidized from government revenue (WHO 2010).

\section{Community based Health Insurance in Developing Countries}

In many developing countries, formal insurance is viewed as the province of the rich (Tabor, 2005). Informal insurance, by contrast, is already is part of their daily lives. Many low income households actively participate in welfare associations such as burial societies, rotating credit societies, cooperatives or other reciprocal exchange systems. One of the innovative features of CBHIs is that it introduces a complex financial concept health insurance as an extension to an already familiar form of informal social interaction.

In sub-Saharan Africa, out-of-pocket expenditures constitute approximately $40 \%$ of total health expenditures, imposing financial burdens and limiting access to care in some of the poorest countries around the globe (Mbengue, 2011 and $\mathrm{FMOH}, 2010$ )

\section{Community based Health Insurance in Ethiopian Context}

The Government of Ethiopia in collaboration with USAID, Abt Associates Inc. and CARE Ethiopia launched a pilot CBHI scheme. The scheme was established with the aim of enhancing access to health care and reducing the burden of out-of-pocket (OOP) expenditure. This voluntary health insurance for rural households and urban informal sector workers was rolled out in 13 districts located in four main regions (Tigray, Amhara, Oromiya, and SNNPR) of the country (Abt Associates 2008, Derseh et al. 2013).

As a starting point, thirteen districts were selected in four major regional states in Ethiopia for implementation of the pilot scheme. The aim was to reduce financial barriers and improve access to health services by reducing the burden of OOP expenditure (Kagubare 2006). The pilot program scheme covered both outpatient and inpatient healthcare services in public facilities with the aim of enhancing access to healthcare.

While the scheme has been introduced by the government, it is 'community based' in the sense that the community determines whether or not to join the scheme and is subsequently involved in scheme management and supervision. In particular, after being exposed to a range of awareness creation activities a general assembly at the village (kebele) level decided whether or not to join the scheme (a simple majority had to support the decision) and then households decide individually whether to enroll in the scheme. In order to reduce the possibility of adverse selection the unit of membership is the household rather than the individual and new members can use their CBHI card to get healthcare services after waiting for at least for one month (FOMH, 2008).

The Health Care Financing strategy, implemented over the past 15 years, is meeting its objectives. It has provided greater autonomy to health care facilities and mobilized revenue for facilities, including primary care facilities, by reforms such as establishing facility boards, retaining user fees, outsourcing non-clinical services, opening private wings in public hospitals as an income-generating and retaining mechanism for medical professionals and health facilities, and introducing a third-party payer for fee waived patients (EHIA, 2015). 


\section{Empirical Literatures \\ Performance criteria of Community Based Health Insurance \\ Enrollment}

An extensive WHO review was made in 1998 (henceforth called WHO Study) concerning 82 non-profit health insurance schemes for people outside formal sector employment in developing countries. It was observed that very few of these schemes covered large populations or did not even cover high proportions of the eligible population (Carrin 2003).

\section{Factors that influence performance} Factors affecting membership

Many factors can determine the society to be member or not member of CBHI among them Affordability of contribution, unity of enrollment, Distance, timing of collecting, quality of care and trust (Carrin 2003).

\section{Affordability of Contribution}

Not unexpectedly given the voluntary character of CHIs, affordability of premiums or contributions is often mentioned as one of the main determinants of membership. A number of schemes in the WHO Study had addressed the issue of affordability. For instance in the Nkoranza scheme in Ghana, the estimated cost of contributions varied from 5 to $10 \%$ of annual household budgets. It was recognized that such contributions could be a financial obstacle to membership. Contributions are also generally levied as flat sums, which is a disadvantage for the poorest: flat contributions are regressive, a flat-rate contribution as a percentage of income being higher for poor than for the non-poor (Carrin, 2003:14).

\section{Unit of enrolment}

It is another factor that affects the membership of community based health insurance.

Achieving adequate membership rates is likely to be easier when households or even villages, cooperatives or mutual benefit societies are taken as the basis of membership. In the WHO Study, almost half of the schemes surveyed had the family as the unit of membership. A number of schemes had actually switched to this type of membership, after experiencing problems of adverse selection, as a result of families signing up ill family members or family members most prone to consume health care. Also, most of the case studies reviewed in the WCA study had an automatic family coverage Atim (1998, p.42) as cited by carrin (2003: 16).

\section{Distance}

Membership rates are often determined by the distance of the household's home from the nearest health facility where (insured) services are provided. For instance, According to Desmet et al. (1999,p.928) in the GK scheme, membership among the two lowest socio-economic groups appeared to be related to distance: up to $90 \%$ of that target population from nearby villages subscribed, whereas only 35\% did so for the target population in the distant villages (Carrin, 2003:17).

\section{Timing of collecting}

The timing of collecting the contributions may matter for membership, although little empirical evidence is available. From the WHO Study, it was observed that schemes in urban areas were more inclined to establish monthly or quarterly contributions so as to match the income patterns of urban informal sector workers. Annual contributions seem to be prevalent among schemes in rural areas. However, in some schemes, such as the ORT scheme, payment schedules were held flexible, with monthly, quarterly or semi-annual payments. Flexibility was introduced as it was judged that few households were able to pre-pay for a one year or even six-month membership (ibid).

\section{Quality of care}

The quality of care offered through the CHI is another factor to be considered particularly, rapid recovery, good health personnel, good drugs and a nice welcome at the participating health facilities as the most important features of quality (ibid). 


\section{Trust}

The existence of entry-points in the community, such as a micro-credit scheme, a development cooperative or other social groups, may facilitate the establishment of CHI. Trust can be enhanced when people see that their preferences matter (carrin 2003).

The Hillina (2014) identified that human capital variables such as household head age, education, attend local meeting and participate in PSNP, awareness level regarding the program have a positive impact that household heads would become members/participants of the scheme while accessibility to credit negatively influence for their decision.

According to Bedacho et al. (2016) overall household satisfaction with CBHI was $91.38 \%$. Moreover, there was a significant association between health service provision and CBHI members' satisfaction scores. For instance, household heads that strongly disagreed with laboratory services provision had an average 0.878 decrease in CBHI satisfaction score compared to household heads that strongly agreed. CBHI process- and management-related factors were also significantly associated with satisfaction.

Generally, many factors can determine the performance of CBHI in developing countries particularly, in Ethiopia hence, this study focused on the practices of the CBHI and responsible factors for the less enrollment of CBHI.

\section{Research Methodology and Methods:-}

The study used both primary and secondary data in order to get a view on the practices of CBHI and its challenges in regional government. The primary data would be collected from beneficiaries of CBHI through questioners, interview and observation.

\section{Research Design}

The design selected for research should be the one most suited so as to achieve an answer to the proposed research question Parahoo, (2006) cited by Diriba, (2013). For this particular study the researcher collected both qualitative $\&$ quantitative data on the CBHI practice \& challenges. This research study used the descriptive method of study. It presents facts \& reality about the CBHI practice \& challenges at existing condition in the area of the study.

Statistical analysis of the research was descriptive statistics to reveal the current situation on the CBHI practice \& challenges.

The main survey instrument used for this study was questionnaire. The use of the survey allowed the collections of large amount of data from large population in highly economic way as Saunderes et al (2009: 144) cited by Diriba, (2013). The data analyzed quantitatively \& qualitatively using descriptive.

\section{Study and Sample population}

In these study beneficiaries of CBHI, Employees of CBHI at woreda level are the main bodies or a participant that was used as sources of data via the tool of questioner and interview. Participants for interview case were selected by using purposive sampling. But In this district there are 35 local villages out of this 5 villages were selected by simple random sampling and in order to avoid biasness of village selection lottery method will be used to get five villages out of 35 existing villages in which CBHI beneficiaries are living.

Among total population 2,143 was indigent member of the population whereas 10,911 of them was paying member (Non-indigent) of beneficiaries so the total number of CBHI beneficiaries in Gimbichu district are 13,054.

\section{Sample Design \\ Sample and sample size determination}

The total population is 13,054 under this study only those beneficiaries joined before two years since the starting of the scheme at Gimbichu can be considered as source of information this due to the beneficiaries can provide good understanding and know-how of the scheme. As firsthand information acquired from the district CBHI office shows that senior members of the scheme were 450 in number out of 13,054. Hence the sample size can be down from 450 members of CBHI both indigent and non-indigent member of the $\mathrm{CBHI}$.

The rule of thumb cited in Kevin Durrheim, (2006) was used 30\% of sample size for small population up to 1000. Hence, this rule is used for this study in order to decide the simple size formula accordingly, 450 (30\%) which is 
135. The primary data for this study was collected from 135 beneficiaries by using structured questioner out of five selected villages.

\section{Sampling Technique}

For this study the stratified sampling technique was used; it is used to minimize the data biasness from each local villages and the population in each sample was sub-divided into subpopulations or strata. Since the population is homogenous in nature a simple random sampling technique will be conducted within each of the strata and the samples selected from each stratum by using lottery method.

The researcher has hand-picked respondents interviewed question from the Gimbichu woreda of community based health insurance employees and regional CBHI. Namely, Adama baranch manager, CBHI data coordinator of Gimbichu, Woreda health bureau manger, coordinator of woreda CBHI so, interview were conducted with this officials.

\section{Types of data and data collection techniques}

This study was based on the findings of primary and secondary data collected from primary and secondary sources

\section{Primary data collection technique}

The following were primary data collection tools that will be used in this study:

\section{Questioner:}

Self-administer questionnaire would be designed and administered to 135 individuals selected based on sample selection technique outlined above. The questionnaire had structured nature and is self-administered.

\section{In-depth interview:}

the researcher had collected data through in-depth interview from four individuals in the woreda, \& zonal offices. Respondents contacted for the in-depth interview was selected purposively by the researcher as key informants on the basis of their closeness to the implementation (enrolment) of community based health insurance.

\section{Secondary data collection method}

The secondary data was gathered from official sources such as Ethiopian government health Policy, health plans, reports and manuals.

\section{Methods of data analysis}

The study was applied qualitative data analysis methods depending on the nature of the data collected. The data gathered through structured questionnaire was processed via SPSS (Statistical package for social science) of version 24 in order to gate statistics result \& expressed through frequency and percent.

\section{Data Presentation modality}

The result of the study from the questioner would be presented via frequency and percentage. Data collected through interview in the form of case stories with direct word of the respondents were presented in the analysis part.

\section{Ethical Standards}

According to Brynard et al (1997) as citied by Shafudah, (2011) it is unethical to a researcher to present a biased report or not to report the truth as it is. Hence, this study will present fact and unbiased report based on the primary data of the respondents and personal observation.

Required information about the research will be written on the cover page of the questioner \& interview so the information provider can read it $\&$ understand before they provide the required information. The questionnaire will be translated to the mother tang of the respondent's i.e. Afan Oromo in order to make the questioner easily understandable \& clear. Undertaking research study conducted elsewhere by somebody is plagiarism so here; any cited paper for the purpose of this study is given credit for that specific author.

\section{Data Presentation and analysis}

\section{Socio-economic demographic background of the respondents}

Regarding the gender of the respondents as indicated in the Table 4.1 of below $60 \%$ of them are male respondents where as $40 \%$ of them are female respondents. From this data one can infer that male householders are highly 
enrolled in the insurance than the female beneficiaries this signifies that female headed households show less percentage in enrollment as compared to male headed households.

Table 4.1:-Statistics of Household characterstics

\begin{tabular}{|c|c|c|c|c|}
\hline S. No & Variables & & Frequency & Percent \\
\hline \multirow[t]{3}{*}{1.} & \multirow{3}{*}{ Gender } & Male & 81 & 60 \\
\hline & & Female & 54 & 40 \\
\hline & & Total & 135 & 100 \\
\hline \multirow[t]{5}{*}{2} & \multirow[t]{5}{*}{ Age } & $18-48$ & 85 & 63 \\
\hline & & $49-69$ & 42 & 31.1 \\
\hline & & $70-90$ & 7 & 5.2 \\
\hline & & Missing & 1 & 0.7 \\
\hline & & Total & 135 & 100 \\
\hline \multirow[t]{5}{*}{3} & \multirow[t]{5}{*}{ Marital Status } & Single & 8 & 5.9 \\
\hline & & Married & 100 & 74.1 \\
\hline & & Widowed & 13 & 9.6 \\
\hline & & Divorced & 14 & 10.4 \\
\hline & & Total & 135 & 100 \\
\hline \multirow[t]{6}{*}{4} & \multirow[t]{6}{*}{ Occupation status } & Farming & 86 & 63.7 \\
\hline & & Trade & 22 & 16.3 \\
\hline & & Laborer & 15 & 11.1 \\
\hline & & No occupation & 7 & 5.2 \\
\hline & & Others & 5 & 3.7 \\
\hline & & Total & 135 & 100 \\
\hline \multirow[t]{3}{*}{5} & \multirow[t]{3}{*}{ Education status } & Illiterate & 72 & 53.3 \\
\hline & & Literate & 63 & 46.7 \\
\hline & & Total & 135 & 100 \\
\hline \multirow[t]{4}{*}{6} & \multirow[t]{4}{*}{ Family Size } & $1-5$ & 100 & 74.1 \\
\hline & & $6-10$ & 34 & 25.2 \\
\hline & & $>10$ & 1 & 0.7 \\
\hline & & Total & 135 & 100 \\
\hline
\end{tabular}

Source Own Computation (2018)

Concerning the age of the respondents as the data in the table 4.1 of above indicates majorities of the beneficiaries of the respondents are young and middle aged or in productive age group but only $5.2 \%$ of them are old enough members of the scheme. This data shows that majority of insured group in terms of age are very young and middle age household (productive age). Which this shows working age has a positive effect to enroll.

To compare the marital status of the respondent's majority (74.1) of them are married households enrolled in the CBHI followed by divorced (10.4\%), and widowed (9.6\%) the lest percentage is occupied by bachelor person (5.9\%). From this data one can infer that majority of households having family (married) are highly insured. Regarding the occupation of the beneficiary's majority of them $(63.7 \%)$ engaged on the farming sector of the economy. CBHI is for the informal sectors \& those lead their lives on agricultural sectors (EHIA, 2014). Hence, the majority (94.8\%) of them engaged on the informal sectors of the economy in which the health insurance coverage is made by being membership of community based health insurance. Regarding the education status of the respondents majority $(53.3 \%)$ of them are illiterate member of the community based health insurance where as $46.7 \%$ of them are literate members of the insurance. The family size of participants maximum and minimum is 10 and 1 respectively meaning majority (74.1) of them have the family size of 1-5 whereas 25.2 of them have 6-10 family size. As different literature Such as Guy, (2003) shows that family size can be considered as factors responsible for the poor access to health service \& patients satisfaction in less developing countries. As survey of 
2009 that conducted by WHO shows that in Ethiopia the number of hospital beds per 10,000 people were 2 which are very small as compared to other sub-Saharan African countries.

\section{Community Based Health Insurance benefit and its challenges}

As part of its health care financing strategy in general and its health insurance strategy in particular, the Government of Ethiopia endorsed and launched community-based health insurance (CBHI) schemes in 13 pilot woredas in Amhara, Oromia, Southern Nations, Nationalities, and Peoples (SNNP), and Tigray regions in 2010/11 to provide risk protection mechanisms for those employed in the rural and the informal sectors. Three years on, the government has decided to scale up CBHI, with schemes in 161 woreda, (EHIA, 2013).

After three years of piloting, the government decided to expand CBHI schemes to 161 woredas of the country. Aleltu is among districts found in Oromiya that selected for scale up of CBHI. In Aleltu district the CBHI was launched in 2014. In this regard beneficiaries were asked when they started enrolling in the scheme.

The following fig 4.1 demonstrates respondents report on the when you started to enroll in the CBHI hence analysis and interpretation is made.

\section{When you started Enrolling in CBHI?}

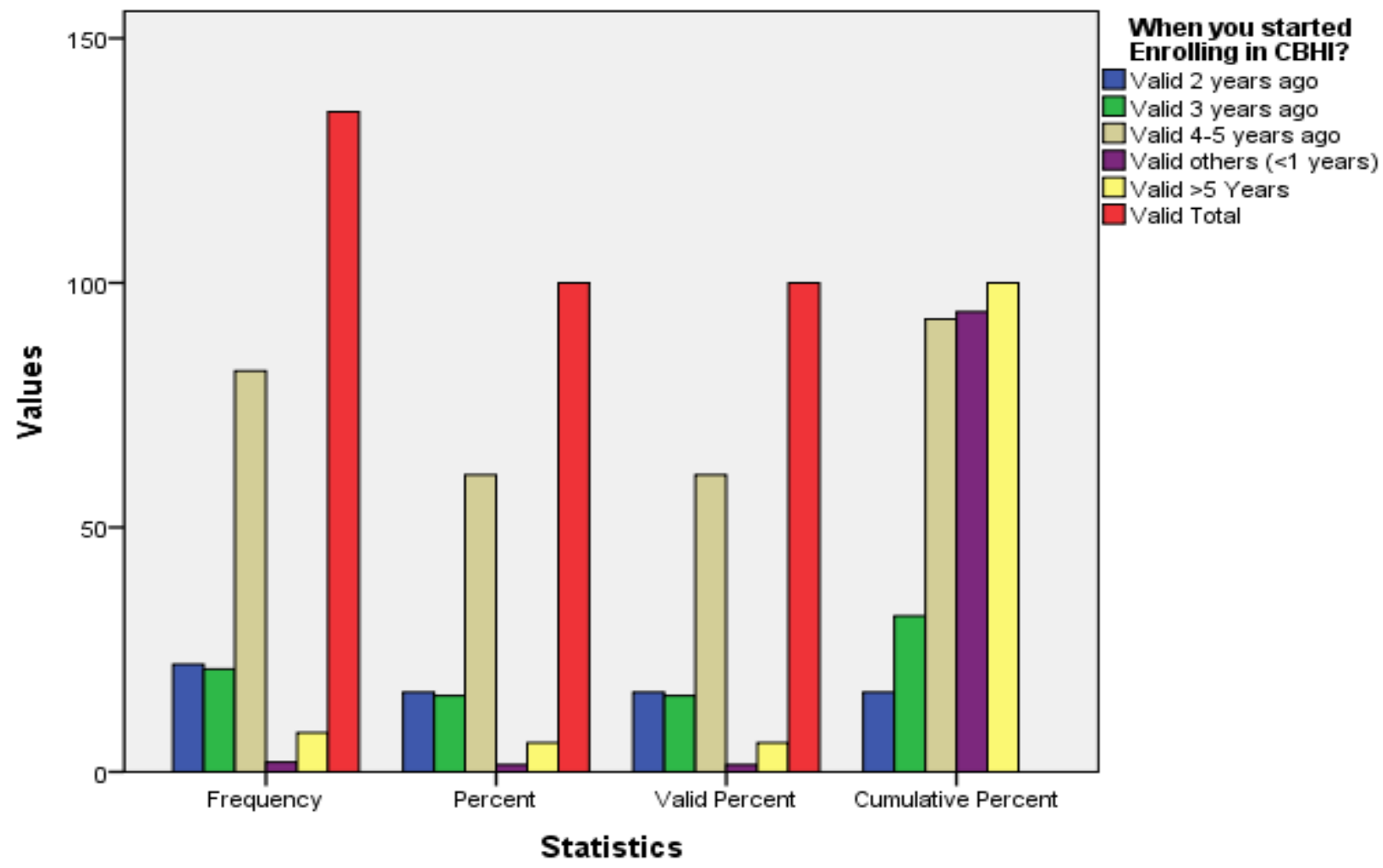

Fig 4.1:-Starting year of the beneficiaries in CBHI

Source: Own Computation (2018)

From total respondents beyond half percent (60.7\%) of them become the member of the scheme since 2014 (before 4 years ago). This shows that majority of the respondents being enrolled since the starting time of the CBHI at Gimbichu woreda that is since 2014 the introduction of the health insurance in Ethiopia is infinity.

Response on: Before CBHI how did you covers your medical expense?

According to Meghan, (2010), more than half of health expenditure in poor countries is covered by out of pocket (OOP) payments incurred by households. An increase in such expenditure can have catastrophic effects and may 
deplete a household's ability to generate current and future income and have inter-generational consequences as households may be compelled to incur debt, sell productive assets, draw down buffer food stocks, or sacrifice children's education.

Regarding this the following table 4.2 reveal the insured households report on their previous history of health cost coverage before they insured in the community based health insurance. The result of the report is interpreted \& analyzed as follows.

Table 4.2:-Before CBHI how did you covers your medical expense?

\begin{tabular}{|c|l|c|c|c|c|}
\hline \multicolumn{2}{|c|}{ Valid } & Frequency & Percent & Valid Percent & Cumulative Percent \\
\cline { 2 - 6 } & OPP & 115 & 85.2 & 85.2 & 85.2 \\
\cline { 2 - 6 } & $\begin{array}{l}\text { We were using traditional } \\
\text { way of treatment }\end{array}$ & 13 & 9.6 & 9.6 & 94.8 \\
\cline { 2 - 6 } & Ikub or Idir & 2 & 2.2 & 2.2 & 97.0 \\
\cline { 2 - 6 } & $\begin{array}{l}\text { Other (Religion wise \& } \\
\text { traditional medicines) }\end{array}$ & 2 & 1.5 & 1.5 & 98.5 \\
\cline { 2 - 6 } & Total & 135 & 100.0 & 1.5 & 100.0 \\
\hline
\end{tabular}

Source: Own Computation (2018)

Concerning the health cost coverage of households before enrolling in CBHI Concerning the health cost coverage of households before enrolling in CBHI $85.2 \%$ of respondents used the out-of pocket payment (OOP) to cover their health expense before they enrolled in $\mathrm{CBHI}$; whereas $9.6 \%$ of them were using borrowing in order to cover the health cost. But $2.2 \%$ of them were using traditional way of treatment followed by traditional way of saving by Ikub or Idir while $15 \%$ of them using other method such as religion wise and traditional medicines in order to overcome the medical costs. From this data one can infer that the introduction of health policies particularly, community based health insurance save the people from incurring to huge health costs by reducing the people dependency from out of pocket payment (OOP).

\section{Response: On improvement of health status}

Here, respondents were asked whether their health status is improved after enrolling in CBHI. The following fig 4.2 of below presented the frequency of respondents report. Under the fig necessary analysis \& interpretation is made according to the question in this part.

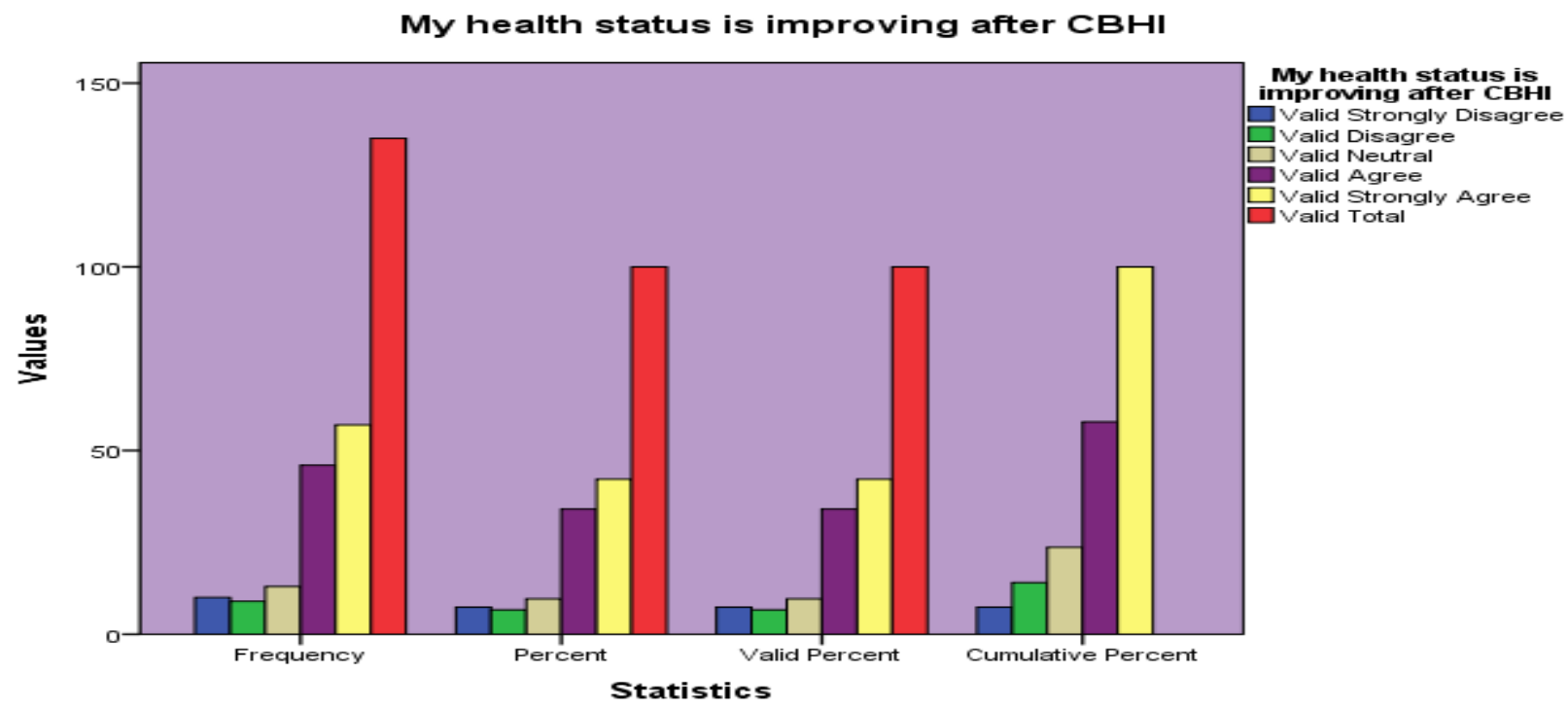

Source: Own Computation (2018)

Fig 4.2:-Improvement of health status 
Regarding the health status of the households after enrolling in the CBHI as the data in the above table (4.2) shows that beyond half of the respondents $(76.3 \%)$ responded that their health status is good and improved after starting enrolling in the CBHI; but from total respondents $14.1 \%$ of them replied that their health is them as with previous or does not improved by being the member of the insurance; whereas $9.6 \%$ of them are neutral concerning this questions. This suggested that CBHI is not only improving the health expense (health finance) of local households it also improving the health status of the households.

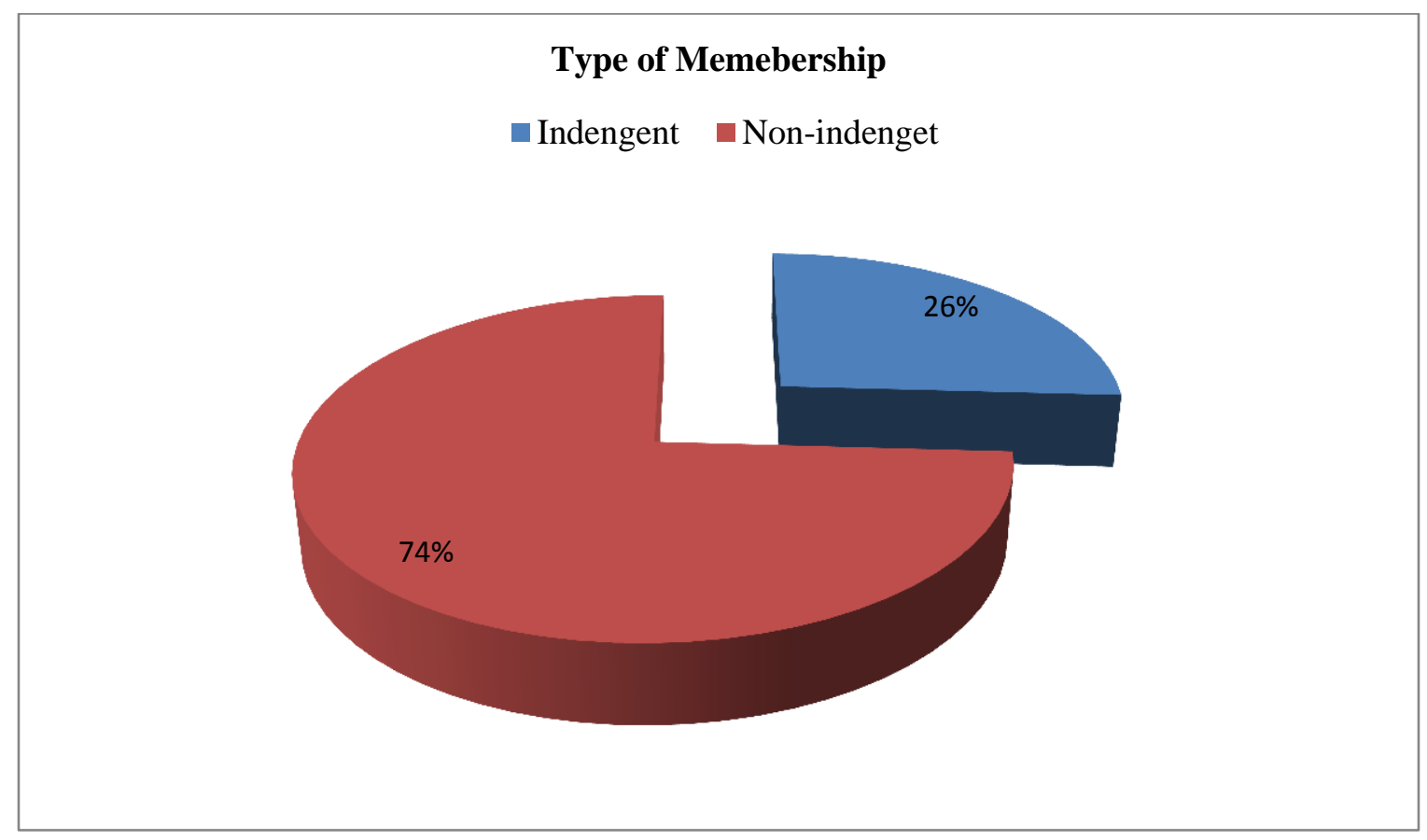

Source: Owen Computation (2018)

Fig 4.3:-Type of Membership

Regarding the membership type as indicated in the above fig 4.3 among total respondents $26 \%$ of are indigent type of member they are getting the health services freely or without any payment this is the category of very poor households, But $74 \%$ of them are non-indigent member of households this category of households is getting health service via paying the premium yearly. This shows that the scheme is giving the service to the poor households without any payment. The sources of income for the scheme are government, its members \& donors. The number of paying group should exceed the number of non-paying member in order to make the financial capacity of the scheme strong. From the three sources of finance the donors is unrealistic \& it is situational as money countries experience like Rwanda shows that in order to make the scheme strong enough they focused on the immediate sources of finance should be the premium payment collected from the member \& with support from the government. As we see from the survey data in fig (4.3) the number of the paying member exceed the number of non-paying group this is good for infant $\mathrm{CBHI}$ in order to make it strong enough in terms of scheme package. The increased and improved cash flow has had a positive effect on the availability of drugs and other supplies, which in turn has improved the quality of health services the facilities provide.

Interview question is conducted with the woreda officials of the scheme on the current total number of insurance members and accordingly " the total number of indigent group were 2,380 and non-indigent (paying) group of insurance were 10,911 so total numbers of the scheme were 13,291" (Interview with officials).

\section{Response on: Do you renewal your membership ID on time}

The literature suggests that there are four factors that are most likely to influence renewal rates: the quality of care on offer, health status, and affordability of insurance and information failures. The last issue includes a lack of understanding of insurance and insufficient information on how to use the insurance policy. High dropout rates clearly threaten the sustainability of such schemes, even if initial uptake is high Angaw, (2015). Regarding this 
beneficiaries were asked whether they are renewed or not their membership insurance on time. The following fig 4.5 presents beneficiaries report. Consequently analysis \& interpretation is made below the fig.

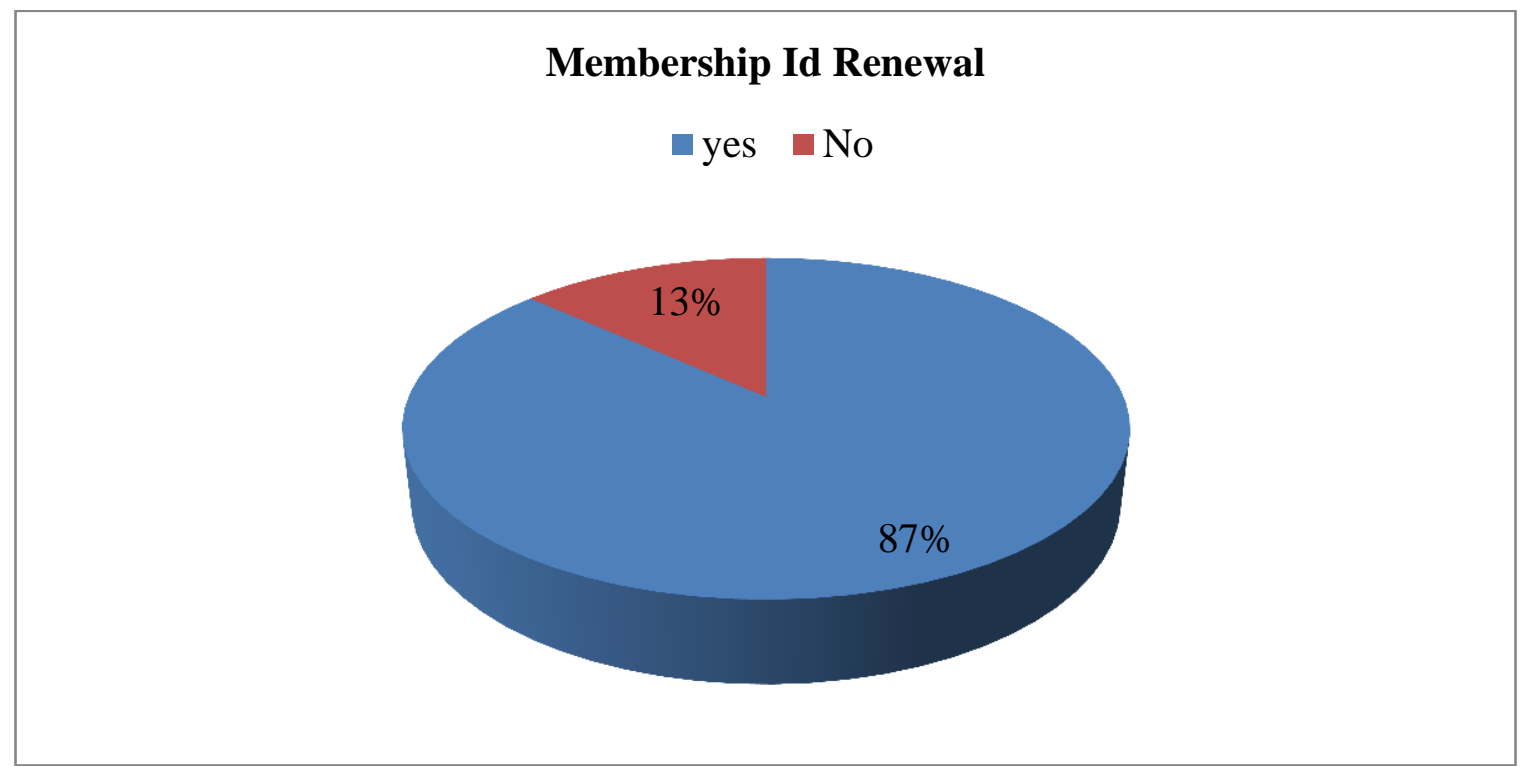

Fig 4.4:-Membership Id Renewal

As indicated in the above data majority (87\%) of them replied that they renewing their ID before the due date but $13 \%$ of them were not renewing their insurance ID on time. From this data on one can infer that the majority of households have good trend on renewing their membership Id on time that is good aspect for healthy development and expansion of the scheme.

Regarding the activities made on reducing the delay on membership renewal they responded that "to delay of membership renewal which can be immediate cause for leaving membership activities such as indenting the immediate reason why they haven't renewed their membership and increasing awareness of the household" (Interview with officials).

\section{Response on: Am happy by being the member of CBHI}

The following table holds respondent's response (report) on their attitude/ feedback towards I haven't get any advantage enrolling in the CBHI.

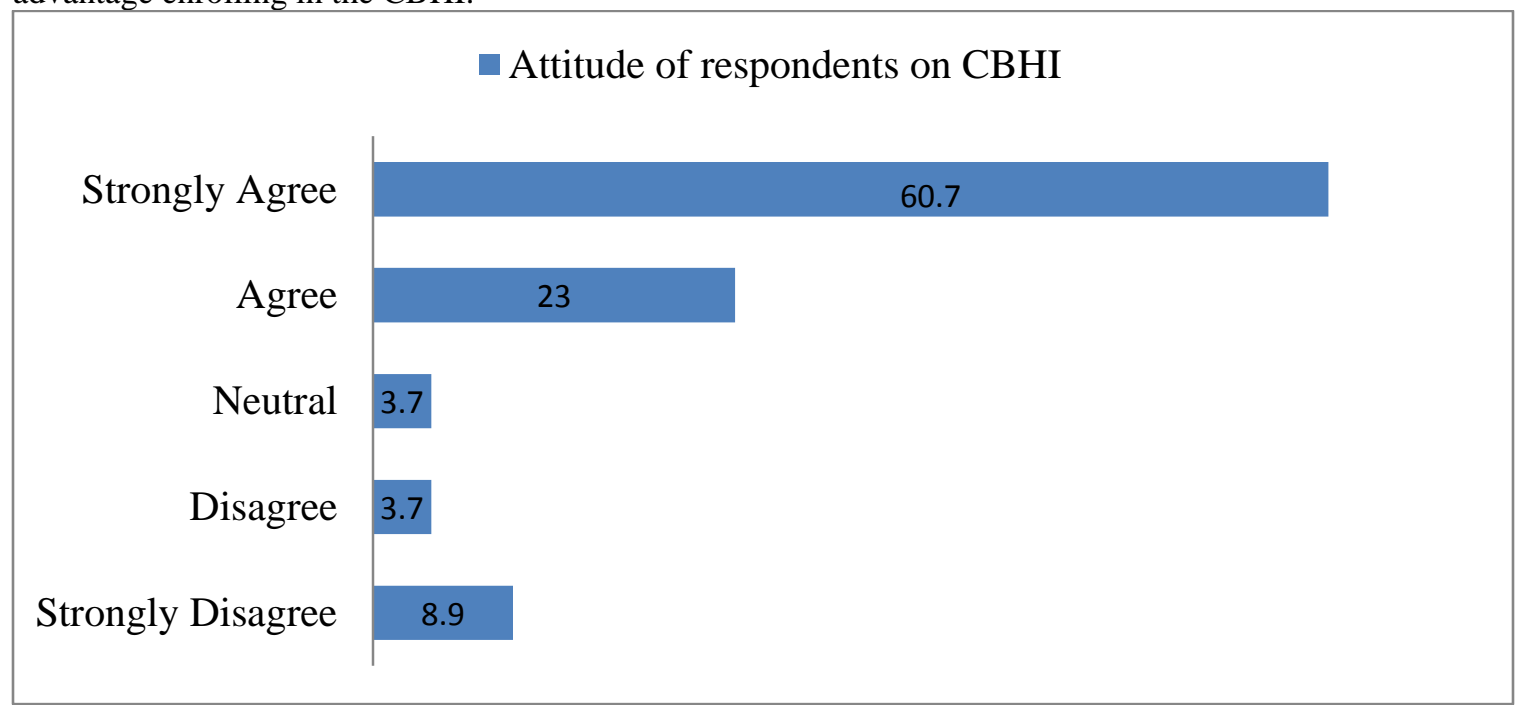

Source: Own Computation (2018)

Fig 4.5:-Attitudes of respondents on CBHI 
As data presented in the above fig 4.5 shows that among total respondents beyond half (83.7\%) of them responded that currently their happy by being the member of CBHI; but $12.6 \%$ of them were not by their membership of the insurance. From this data one can infer that majority of beneficiaries were happy with the insurance.

In open ended questioners beneficiaries were asked that what benefit they acquired after joined the CBHI; Inpatient service, Outpatient service, surgery service, diagnosis service (Laboratory, CT scan and others), medicine service, this all services is provided freely, covered by insurance coverage so it save the people from coast (even fear from health expense).

Major factors influencing performance of CBHI; Affordability of contributions, Unit of enrolment, Distance, Timing of collecting, Quality of care \& Trust (Guy, 2003: 14-15). Regarding factors determining the CBHI performance in this sub section of the study insured members of households were asked about the current premium level (affordability contribution) \& timing of collecting which is one of the top determinants of CBHI performance.

Table 4.5:-Premium is affordable

\begin{tabular}{|l|l|c|c|c|c|}
\hline \multirow{3}{*}{ Valid } & Frequency & Percent & Valid Percent & Cumulative Percent \\
\cline { 2 - 6 } & Disagree & 7 & 5.2 & 5.2 & 5.2 \\
\cline { 2 - 6 } & Agutral & 14 & 10.4 & 10.4 & 15.6 \\
\cline { 2 - 6 } & Strongly Agree & 46 & 34.1 & 34.1 & 49.6 \\
\cline { 2 - 6 } & Total & 68 & 50.4 & 50.4 & 100.0 \\
\hline
\end{tabular}

Source: Owen Survey data (2018)

From total respondents majority of them $(84.5 \%)$ responded that the current health insurance premium level is affordable; but $5.2 \%$ of them believed that the current premium is not affordable by their income level. One can infer that members (indigent) are feeling good with the current premium payment.

\section{Response on: Premium collection is convenient}

Major factors influencing performance of CBHI; Affordability of contributions, Unit of enrolment, Distance, Timing of collecting, Quality of care \& Trust (Carrin, 2003: 14-15).

From the WHO Study, it was observed that schemes in urban areas were more inclined to establish monthly or quarterly contributions so as to match the income patterns of urban informal sector workers, (ibid:16).

The following fig 4.6 shows the report of the respondents regarding the question \& necessary interpretation \& analysis is made.

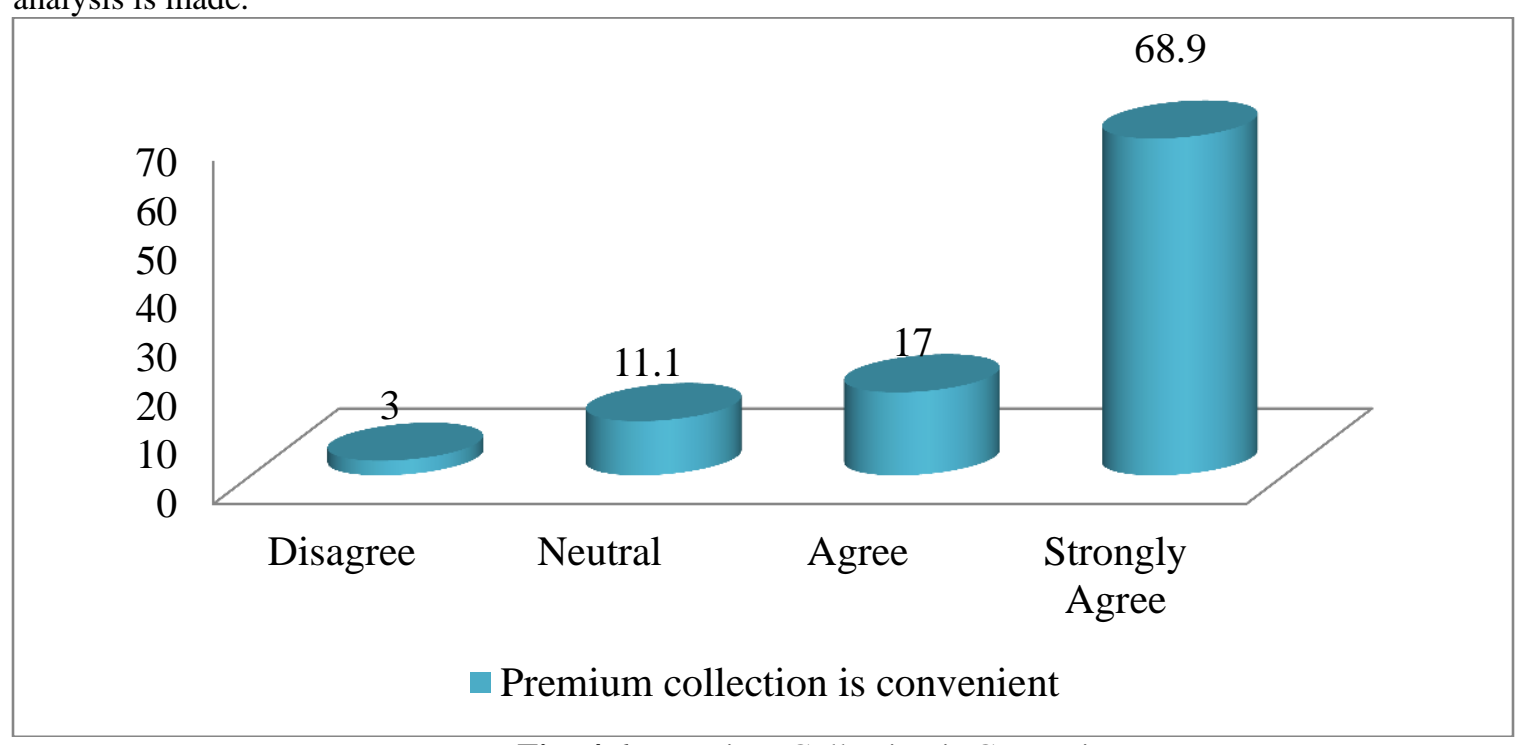

Source: Owen survey data (2018)

Fig: 4.6:-Premium Collection is Convenient 
According to the survey data in the above fig 4.6; from total respondents majority (85.9\%) of them responded that the time for payment of the premium is convenient; but for $3 \%$ of the respondents it is not convenient while $11.1 \%$ of them are neutral on the questions. From this data one can infer that the collection of money from the members of the insurance is covenant.

As the response of employees regarding the timing of collection they are using the premium collection during the harvest time that mean at the end of the year which is convenient time for the households to pay the premium since it is time they have cash at their hand.

Interview was conduct with higher officials of the scheme at woreda level when CBHI premium is collected 'the premium is collected most of the time August 1-September 30, this month is selected because of it is time harvesting hence famers can get cash at this month" (Interview with officials).

\section{Response on: I trusted the scheme}

In LMICs, while CBHI schemes may be helpful in the short term to address the issue of improving the rural population and informal workers' access to health services, they still face challenges. Lack of funds, poor quality of care, and lack of trust are major reasons for low CBHI coverage in LMICs (Adebayo et al. 2015).

Based this respondents were asked whether they are trusted or not on the scheme and the following fig 4.7 shows respondents response on this so necessary interpretation is given below the fig.

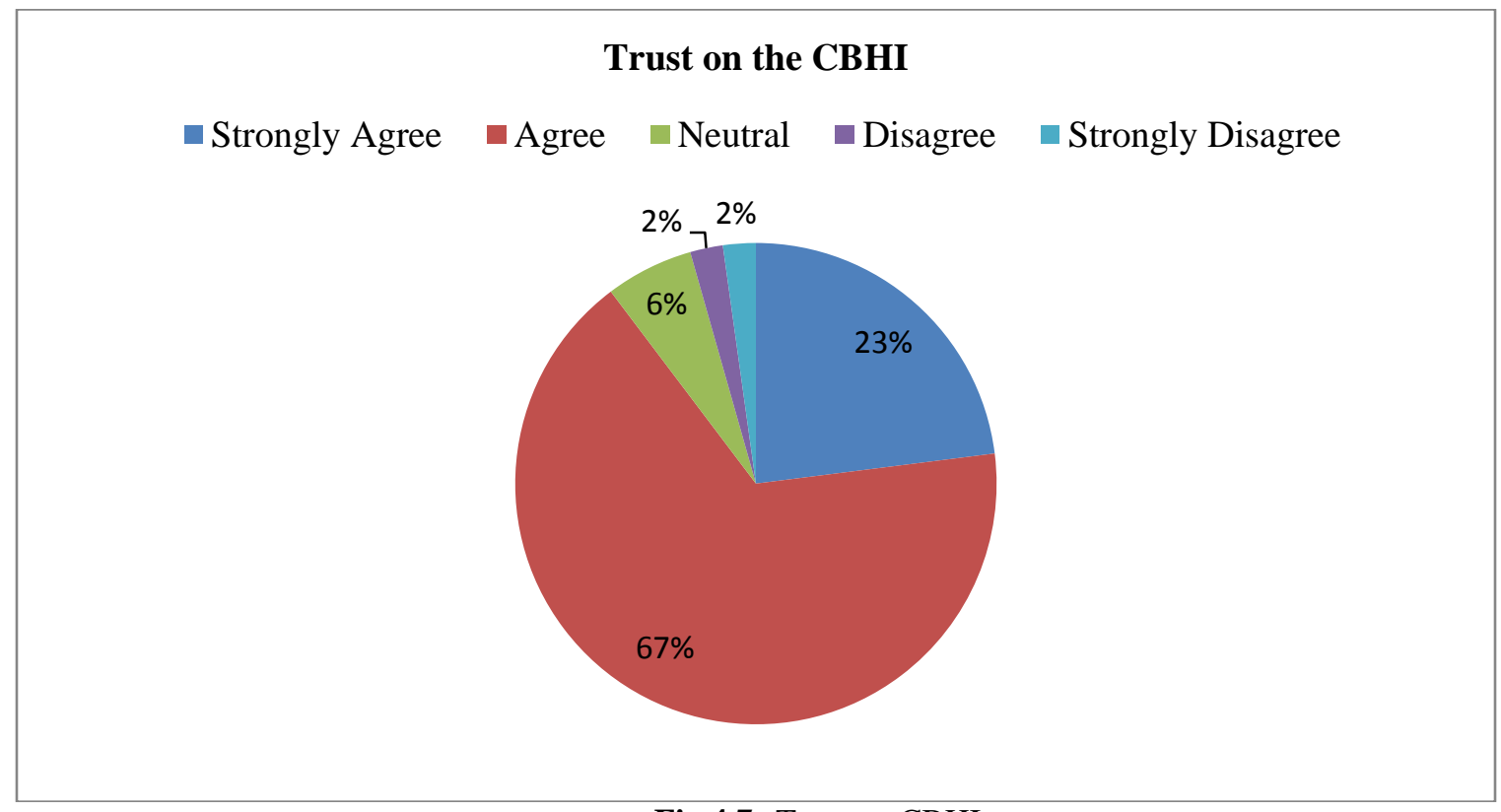

Source: Own survey data (2018)

Fig 4.7:-Trust on CBHI

From the total respondent's majority (90\%) of them responded that they have trust on the scheme only $4 \%$ of them are not interested and trusting the scheme. From this data one can infer that currently many members of the insurance trust the scheme which has positive impact on the entire nature and progress of the scheme particularly, in this studied woreda.

\section{challenges/problems facing the $\mathrm{CBHI}$}

Respondent's response on: How is the health facility utilization mechanism

Poor quality is among challenges of CBHI in LMICs (Adebayo et al. 2015). In this regarding respondents is asked the healthy facility utilization which can determine the quality of care; the following table holds the respondents data on this feedback. 
Table 4.6:-How is the health facility utilization mechanism

\begin{tabular}{|l|l|c|c|c|c|}
\hline \multicolumn{2}{|c|}{} & Frequency & Percent & Valid Percent & $\begin{array}{c}\text { Cumulative } \\
\text { Percent }\end{array}$ \\
\hline Valid & Very Good & 19 & 14.1 & 14.1 & 14.1 \\
\cline { 2 - 6 } & Good & 60 & 44.4 & 44.4 & 58.5 \\
\cline { 2 - 6 } & Satisfactory & 27 & 20.0 & 20.0 & 78.5 \\
\cline { 2 - 6 } & poor & 19 & 14.1 & 14.1 & 92.6 \\
\cline { 2 - 6 } & Very Poor & 10 & 7.4 & 7.4 & 100.0 \\
\cline { 2 - 6 } & Total & 135 & 100.0 & 100.0 & \\
\hline
\end{tabular}

Source: Owen survey data (2018)

According the survey data of table 4.6 beyond half (58.2\%) of the respondents replied that the health facility utilization is averagely good. whereas $20 \%$ of them believed that the facility is average but 21.5 of them below the average. That suggested that the overall health facility utilization in health institution is above the average in the provision of health services via CBHI.

The health facility utilization used by the health institution in providing the health service is low. Access to better health service is determinant factor in the practice of the Community based health insurance. In the provision of better health service, health facility utilization is back bone of the health institution for instance as data of WHO shows that in Ethiopia in 2009, the number of hospital beds per 10,000 people was 2 (while the average availability for Sub Saharan African (SSA) region was 9), the number of nurses and midwives per 10,000 population was 2 (11 for SSA) and that of physicians (generalist and specialist medical practitioners) was only 0.4 (2 for SSA), (WHO, 2010).

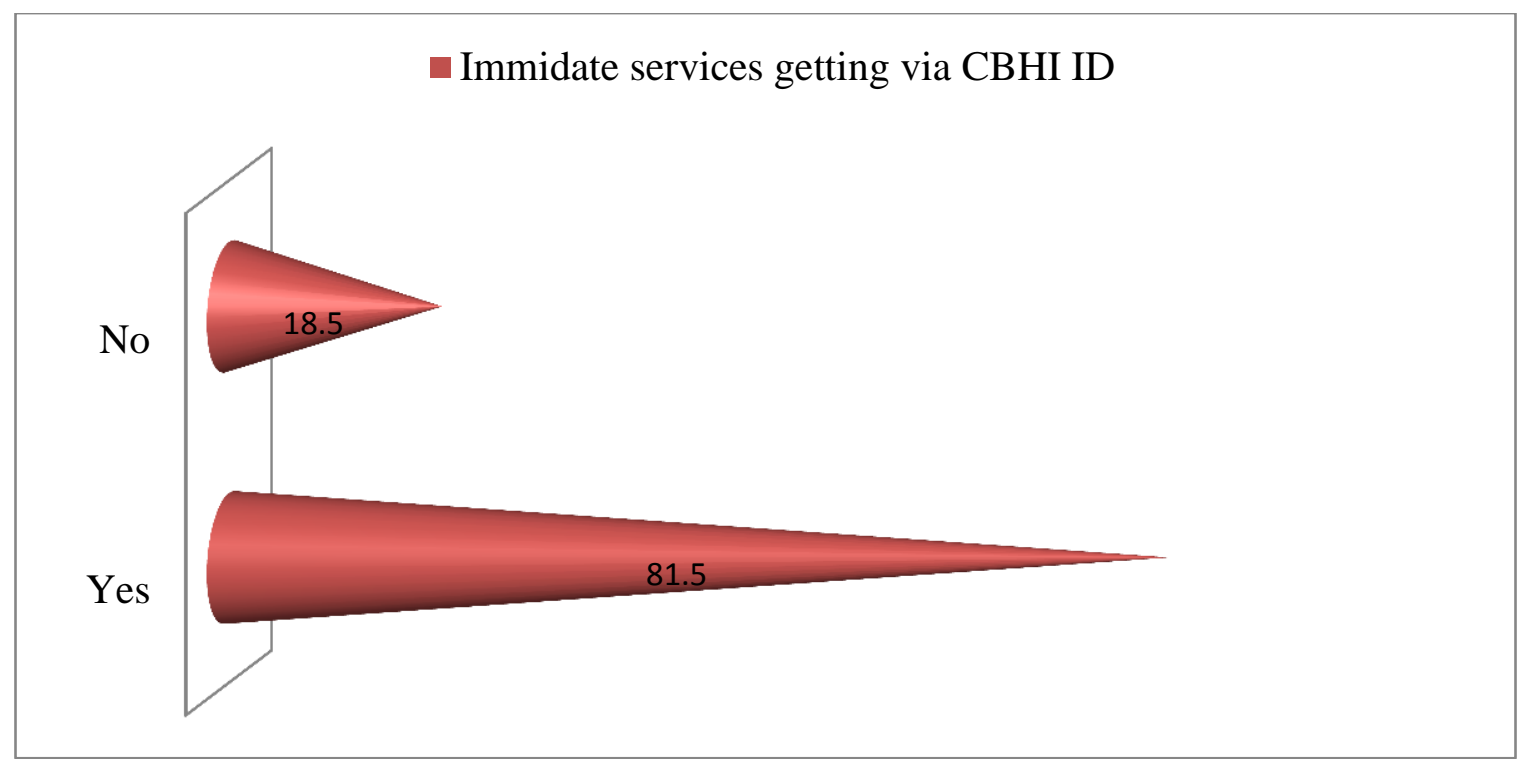

Fig 4.8:-Immediate service getting via you CBHI ID

Source: Own Survey data (2018)

Regarding the respondent's response on whether they are getting immediate service or not via their CBHI membership Id; as the data in the above fig 4.8 shows that from total respondents $81.5 \%$ of them responded that they are getting immediate service by their insurance membership ID. But $18.5 \%$ of them stated that they are not getting service timely due to they are not equal treated with those of out of pocket payment, poor health facility utilization and poor attitude of the service providers (at government hospitals).

\section{Response on: Are you getting medicines}

One of the reasons for non-membership invoked was the fact that members did not have access to better quality care at mission health facilities (Guy, 2003: 17). 
Among the better quality care; getting medicines from the health institution on time is among determinant factors for customer satisfaction. Since absence of better quality care (such as absence of available medicines) can have negative impact on the practice of CBHI. For this matter ensured member of the households were asked to identify whether they are getting medicines prescribed to them or not. Hence the following fig 4.9 contains the report of the respondent's feedback regarding the question \& analysis with interpretation provided below the table.

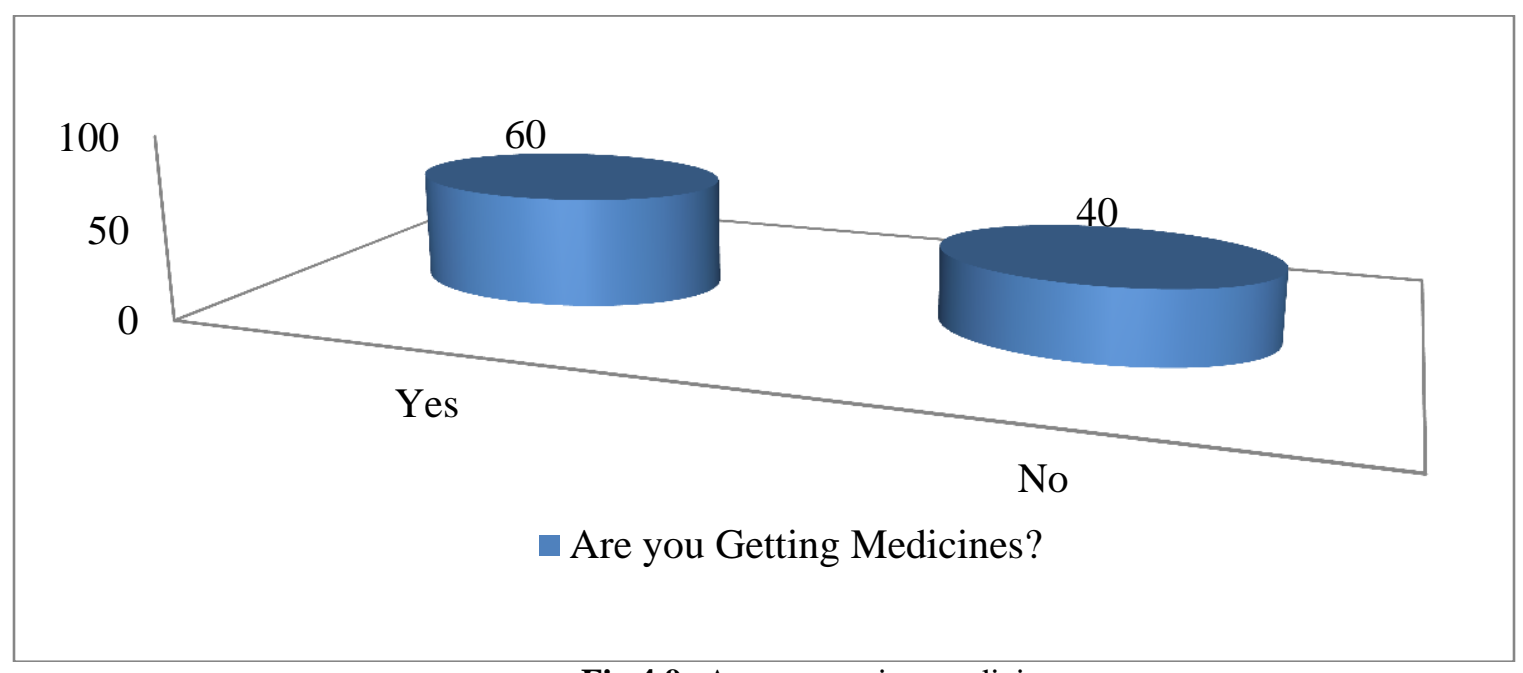

Source Owen survey data (2018)

Fig 4.9:-Are you getting medicines

As survey data in the above fig 4.9 shows that majority $(60 \%)$ of the households responded that they are getting prescribed medicines for their disease after treatment; but (40\%) of them responded that they are not getting medicines prescribed to them from the health post, health center or hospitals. Absence of medicines in one health institution is implication of poor service provision in that specific health institution. This have negative impact on the enrolment rate of CBHI suggests that if the people can't get good service they will be dissatisfied with the service this can cause drop out from the scheme through long run.

This suggests that there is availability of medicines for the members of insurance after them getting treatment at health institutions.

\section{Do you go government hospital by your CBHI card for Refer?}

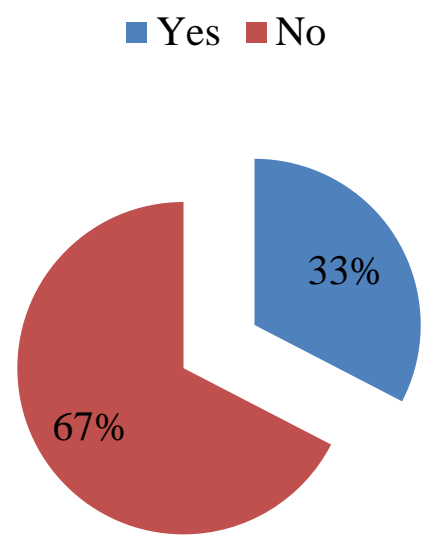

Fig 4.10:-Do you go government hospital by your CBHI card for Refer? 
As indicated in the above survey data of fig 4.10 from among total respondents beyond half of the respondents $(67 \%)$ of them responded that they haven't go hospital for refer cases but only $33 \%$ of them went to hospital for referral cases. From this data one can infer that households are getting the health service from government hospitals by their CBHI Id.

Beside these households those said yes for the above question were asked whether they got good treatment or not at that hospital for their referral cases the hospitals used for referral cases to Gimbichu districts is Bishoftu hospital so from the respondents getting services from this hospital only $10.4 \%$ of them responded that they didn't got from the Bishoftu hospital through their CBHI membership ID. Whereas $48.8 \%$ of them responded that they got good treatment from the hospital via their insurance scheme. The rest percent is covered by neutral respondents $(8.1 \%)$.

Interview were conducted with higher officials of the woreda CBHI on the with which government hospitals currently working for referral cases " currently, for patients those need referral cases we are working with government hospitals such as Bishotu hospital and Adama hospital (Interview with officials).

Table 4.7:-Are you getting equal treatment with those of OPP

\begin{tabular}{|l|l|c|c|c|c|}
\hline \multicolumn{2}{|c|}{} & Frequency & Percent & Valid Percent & Cumulative Percent \\
\hline \multirow{3}{*}{ Valid } & Yes & 83 & 61.5 & 61.5 & 61.5 \\
\cline { 2 - 6 } & No & 52 & 38.5 & 38.5 & 100.0 \\
\cline { 2 - 6 } & Total & 135 & 100.0 & 100.0 & \\
\hline
\end{tabular}

Source: Owen survey data (2018)

Regarding the service treatment with those of OPP beyond half $(61.5 \%)$ of the respondents responded that they are getting equal treatment with patients served on the bases of out of pocket payment (OPP), but $38.5 \%$ of the respondents replied that they are not equally treated with those of getting health service by making direct payment for that health services, based on their open ended question feedback the main reason for their unequal treatment is poor connection between the agreed hospital and the insurance schemes (Implementers of the insurance), poor awareness from the health institution on the scheme and less follow up from the office on the implementation of the scheme in the agreed hospitals.

\section{Interview Questions}

\section{Major challenges facing the woreda while implementing the CBHI}

Regarding this employees states that the major problems happen from implementing bodies are; In the health institution the attitude of the health employees is very less towards the members of the CBHI, there is shortage of medicines, absence of the nearest hospital in the wored, lack of skilled manpower assigned for the CBHI, lack of concern and commitment from the concerned body, the health institution is taking the scheme as extraordinary activities than their major concern or parts of activities, absence of good package (Benefit) to the CBHI employees so majority of the insurance worker are less satisfied, Absence of premium collection in full manner, absence of identifying indigent members as per the rule of the insurance.

From the house holds aspect the following be major problems faced the insurance; Not fulfilling the necessary requirement during registration (such as photograph), Not taking their membership ID on time by presenting at the office, Forgetting their membership ID while going to health institution.

What methods you are using in order to handle the above listed problems?

The following methods is suggested by the officials; increasing the number of CBHI, discussing with community (increasing community participation), Discussing with agreed government hospitals in solving the less commitment of health employees in service provision, working with major stakeholders (health office, regional health bureau, federal ministry of health), Providing necessary training (awareness creation) to employees of health institution, generally working on the problems that dissatisfied beneficiaries of the scheme.

Who are major stakeholders of the CBHI? How your office is working with these stakeholders on the implementation of the scheme? 
Major stakeholders of the scheme include: "Community insurance agency Adama branch, Abt associate INC, PHCU woreda transform project, east showa zone health office. They are helping us by providing training and other logistic help"' (Interview of CBHI officials).

\section{Summery, Conclusion and Recommendation:- Summery}

This paper has examined the community based health insurance practices and to identify possible problems that occur in the implementation of the scheme in the Oromiya regional state, Gimbichu district.

The overall practice (enrollment) of CBHI in the studied woreda is good particularly, on membership handling, premium collection and handling the reducing (controlling) those households from the member. But major problems facing the enrollment are identified both from the implementers and beneficiary's side.

The major findings on major enrollment of $\mathrm{CBHI}$ and challenges particularly from the service provider side is summarized in the following here as follows.

\section{Findings from the Study Practices of the CBHI}

The enrolment of the CBHI in Gimbichu woreda is significant even many people being the member of the insurance since 2014 (60.7\%) this will have positive impact on the progress of the CBHI in the woreda. After the initiation of the insurance in the woreda money the dependency of households on the out of pocket payment (OPP) is reduced by very significant number $(85.2 \%)$ the insurance is not only saving the people from sudden medical expense but their family health status is also improved after enrolling in the scheme $(76.3 \%)$. The woreda is working on boosting the scheme membership especially the non-indigent one currently the number of the non-indigent is exceeding the indigent one $(74 \%)$. In the Gimbichu woreda the current total number of non-indigent members of the insurance is 10,911 whereas indigent member of the insurance is 2,380 so the overall progress of the woreda on membership type especially on the paying group is good.

The study woreda is better on awareness creation to the community on making them to renew their membership ID accordingly, (87\%) are renewing their membership on time, and this has positive impact on the CBHI by reducing the delay on renewing which the cause for becoming out from the scheme. Households are happy with the current premium payment level and its collection time (84.5\%) and (85.9) respectively. The level of trusting the scheme is very good $(90 \%)$ this is significant for the insurance because people trust is one of the factors that can determine the practices of $\mathrm{CBHI}$ in les and middle income countries.

\section{Challenges/problems facing the CBHI}

Many problems has contributed for less enrollment of the scheme; major problems happen from implementing bodies are; In the health institution the attitude of the health employees is very less towards the members of the CBHI, there is shortage of medicines, absence of the nearest hospital in the wored, lack of skilled manpower assigned for the CBHI, lack of concern and commitment from the concerned body, the health institution is taking the scheme as extraordinary activities than their major concern or parts of activities, absence of good package (Benefit) to the CBHI employees so majority of the insurance worker are less satisfied, Absence of premium collection in full manner, absence of identifying indigent members as per the rule of the insurance.

From the house holds aspect the following be major problems faced the insurance; Not fulfilling the necessary requirement during registration (such as photograph), Not taking their membership ID on time by presenting at the office, Forgetting their membership ID while going to health institution.

\section{Conclusion:-}

The enrolment of the CBHI in Gimbichu woreda is significant even many people being the member of the insurance since $2014(60.7 \%)$ this will have positive impact on the progress of the CBHI in the woreda. Number of nonindigent members of the insurance is 10,911 whereas indigent member of the insurance is 2,380 so the overall progress of the woreda on membership type especially on the paying group is good. 
Both demand (In the health institution the attitude of the health employees is very less, there is shortage of medicines, absence of the nearest hospital in the wored, lack of skilled manpower assigned for the CBHI and supply side problems (Not taking their membership ID on time by presenting at the office Not fulfilling the necessary requirement during registration) responsible for less enrollment of the insurance.

\section{Recommendation}

The overall practice of the insurance in the studied woreda is good but the woreda should work on solving problems that are facing the CBHI. It should work with the agreed government hospital in order to improve the attitude of health employs in making the health service better to the insurance members, government officials should be committed (woreda, zonal, regional health bureau and federal ministry of health) enough, From the problems encountered on the enrolling of CBHI is lack of skilled man power \& lack of enough man power in order to solve this problem the agency should recruit new man power from the market $\&$ it should capacitate the exiting employees via giving education opportunity \& training to this employees.

The enrollment rate of CBHI in Gimbichu woreda is increasing from year to year. This is good performance to scale up the insurance $\&$ reducing the out of packet based people \& achieving universal access to health. Beside this the office is working on reducing the drop rate of permanent members. So we can say the CBHI in Gimbichu woreda is on good track on scale up the enrollment \& minimizing the drop out.

Among the factors responsible for dalliance during CBHI registration is that; household is not bring their photograph on time so they will not get their membership Id timely since it is rural area the farmers may not accesses photograph house therefore, the researcher recommend the office to have its own camera to take the photo of household during the registration time.

\section{References:-}

1. D. Wiesmann and J. Jütting (2000). The Emerging Movement of Community Based Health Insurance in SubSaharan Africa: Experiences and Lessons Learned. Africa spectrum 35 (2000) - 2.

2. G. carrin et al (2005). Community-based health insurance in developing countries: a study of its contribution to the performance of health financing systems. Tropical Medicine and International Health. Volume 10 no 8 pp. 799-81.

3. Angaw D. (2015). Essays on evaluating a community Based health insurance scheme in Rural Ethiopia. International institute of social studies.

4. Ahuja, Rajeev and Jütting, Johannes (2004) "Are the Poor Too Poor to Demand Health Insurance?" Journal of Microfinance / ESR Review: Vol. 6 : Iss. 1, Article 2. Available at: https://scholarsarchive.byu.edu/esr/vol6/iss 1/2

5. FMOH. (2014). Quarterly Health Bulletin. Policy and practice Information for action. Addis Ababa: Federal Ministry of Health.

6. WHO. (2010). Health System Financing: The path to universal coverage. Geneva: 15-50.

7. EHIA. (2015). Evaluation of Community Based Health Insurance Pilot Schemes in Ethiopia Final Report. Addis Ababa: EHIA.

8. Haile. (2014). Willingness to join community based health insurance among rural households of Debub Bench District, Bench Maji Zone, and Southwest Ethiopia. . BMC Public health , 14-51.

9. Adebayo et al. (2015). A systematic review of factors that affect uptake of community-based health insurance in low-income and middle income countries. BMC health service research, 15-543.

10. Hilina, H. (2014). Socio Economic Determinants of Community Based Health Insurance. The Case of Kilte Awelaelo District, Tigray Regional State.

11. OECD. (2004). Private Helath insurance in OCEDE countries .

12. Shemeles Abebe (2010). Community Based Health Insurance Schemes in Africa: the Case of Rwanda. Development Research Department of the African Development Bank. 1-.

13. Tabor, Steven R. (2005). Community Based haelth Insurance \& social protection policy. Spcial protection Unit Human Development Network the world Bank.

14. FOMH. (2008). Health Insurance Strategy . Addis Ababa: Federal Ministery of health planning \& program department .

15. G. Carrin (2003). Community based health insurance in developing countries: facts,problem \& perspectives World helath organization. World health organization conference (pp. 20-70). Geneva: World health organization. 
16. Diriba, A. (2013). Roles and challenges of NGOS in poverty alleviation and women empowerenment in kelem Wolega Zone.

17. Kevin Durrheim, D. P. (2006). Research in practice: Apllied methods for social siences. Cape Town: Juta and Company Ltd, 2006.

18. Shafudah, E. (2011). Appraising Performance Management Processes: A Case of the Directorate of Customs and Excise, Ministry of Finance, Namibia. Submitted in Partial Fulfillment of the requirements for the Degree of Master of Science in the Subject Leadership and Change Management at the Leeds Metropolitan University.

19. Meghan, S. (2010). Micro Finance Health Insurance In Developing Countries. wharton Reserach scholars woking paper . 